\title{
Application of spectroscopy for nutrient prediction of oil palm
}

\begin{abstract}
Oil palm crop has been an important source of income to Malaysian economy, thus it is important to ensure the crops obtain optimum nutrient supply to achieve a higher productivity. This study aimed to investigate the ability of near-infrared reflectance spectroscopy for predicting nutrient deficiency of oil palm tree based on its leaf samples. Near-infrared spectral data was measured using a full range spectroradiometer with wavelength ranging from 350 to $2500 \mathrm{~nm}$ from three different frond numbers, namely frond 3 , frond 9 and frond 17. Partial least square method was used to develop calibration and prediction models data for the prediction of nitrogen, phosphorus and potassium of oil palm. The result indicated that the full range spectrometer can be used to predict the nutrient deficiency of oil palm tree based on 30 leaf samples. Frond 17 was found to have a better prediction accuracy than frond 3 and frond 9 . The value of coefficient of determination (R2) for frond 17 for values of nitrogen, phosphorus and potassium of 0.98, 0.98 and 0.98 while frond 3 results with $0.21,0.12$ and 0.19 and frond 9 had values of $0.05,0.49$ and 0.48 respectively. In terms of Root Mean Square Error of Prediction for frond 17 ranged between 1.40 and 1.55 while frond 3 and frond 9 ranges from 0.01 to 0.15 and 0.01 to 0.21 respectively. In summary, spectroradiometer can be used to predict nutrient deficiency in oil palm frond frond 17 using partial least square analysis.
\end{abstract}

Keyword: Oil palm; Nutrients; Deficiency; Spectrometer; Partial least square 